\title{
SOME INEQUALITIES INVOLVING A FRACTAL OPERATOR OF FUNCTIONS ON THE SPHERE
}

\author{
M. A. NAVASCUES
}

Abstract. This paper undertakes the construction of fractal versions of the classical spherical harmonics. Some inequalities satisfied by the coefficients of the iterated function systems defining the fractal functions provide sufficient conditions for the existence of new Hilbert bases of functions on the sphere. This fact confirms their properties of good approximation. The methodology used implies the definition of an operator mapping standard functions into their fractal analogues. The transformation is linear and bounded and some upper bounds of its norm are also established.

Mathematics subject classification (2010): 28A80, 43A90, 33C55.

Keywords and phrases: fractal interpolation functions, spherical harmonics, iterated function systems.

\section{REFERENCES}

[1] M.F. BARnsley, Fractal functions and interpolation, Constr. Approx., 2, 4 (1986), 303-329.

[2] M.F. BARNSLEY, Fractals Everywhere, Academic Press Inc., 1988.

[3] M.F. Barnsley, A.N. Harrington, The Calculus of Fractal Interpolation Functions, J. Approx. Theory, 57 (1989), 14-34.

[4] P.J. DAVIS, Interpolation and Approximation, Dover Publ., New York, 1975.

[5] A. Doneddu, Fonctions Vectorielles. Series. Equations Diferentielles, Ed. Vuibert, 1981.

[6] W. FREEDEN, K. HeSSE, Spline modelling of geostrophic flow: theoretical and algorithmic aspects, Report AMR04/33. School of Mathematics. Univ. of New South Wales, 2004.

[7] H. KALF, On the expansion of a function in terms of spherical harmonics in arbitrary dimensions, Bull. Belgian Math. Soc. Simon Stevin, 2, 4 (1995), 361-380.

[8] A. N. Kolmogorov, S. V. Fomin, Elements of the Theory of Functions and Functional Analysis, Courier Dover Publ., 1990.

[9] M.A. NAVASCUÉs, Fractal polynomial interpolation, Z. Anal. Anwend., 24, 2 (2005), 401-418.

[10] M.A. NAVASCUÉs, Fractal trigonometric approximation, Electron. T. Numer. Ana., 20 (2005), 6474.

[11] M.A. NAVASCUÉs, M.V. Sebastián, Generalization of Hermite functions by fractal interpolation, J. Approx. Theory, 131, 1 (2004), 19-29.

[12] F. RELlich, Eigenwerttheorie partieller Differentialgleichungen. Teil I (Wintersemester 1952/53). Als Manuskript vervielfältigt: Mathematisches Institut der Universität Göttingen, 1953.

[13] G. Sansone, Orthogonal Functions, R. E. Krieger Publ., New York, 1977. 